During the opening decade of the century he worked in collaboration with Henry Head on disturbances of sensation associated with cerebral lesions, drawing from them inferences as to the role of the cerebral cortex in sensory function.

This was a remarkable collaboration, for Holmes, his training soundly anchored in anatomy, not only devised quantitative methods of sensory assessmont, but also was a brake on Head's eager fancy. It will be remembered that Head's early studies with Rivers on the afferent sensory system, though brilliant, had a fatal defect, in that Nature had not provided the structural facilities for the theories which they had put forward. Holmes, therefore, was an essential complement to his partner in this work, and between them they produced a more delicate and precise concopt of the role of the cortex in sensation than any earlier one.

Also during the poriod spent in France, Holmes made a number of valuable studies on disturbances of visual function from brain lesions. These included a somatopic cortical representation of the afferent visual pathway, and the bases of visual orientation and attention. These considerable cerebellar and visual studies were collected and published as a supplement to Brain (of which journal Holmes was editor during 1922-37) in 1956 on his eightieth birthday. Appended to that supploment is a bibliography of his published work which reveals his immense pro. ductivity and the wide range of his thought over the fields of neurological anatomy, physiology, morbid anatomy and nosography.

During the years between 1919 and 1939 Holmes also gained an international reputation as an incomparable teacher of postgraduate students in neurological medicine. These young men flocked to the National Hospital from the British Commonwealth and from the United States to join Holmes's staff as clinical clerks. These clerks and his own house physicians formed a generation of neurologists still to be found in all parts of tho English-spoaking world, holding senior positions in neurological departments. Holmes was an exacting taskmaster to these men, but ho had the gift of lucid and logical exposition so that the 'how' and 'why' of his conclusions and of his diagnoses were apparent. Ho was not a showman anxious to impress, but a born teacher.

Personally, Holmes was a man of great strength and inexhaustible energy and of a forceful temperament, sometimes frightening but never malicious, always gaining the respect and later the affection of those he taught. To be trained by him was a salutary discipline. Committees he loathed, and was an impatient and sometimes intolerant member of them. But for younger men in whom he saw a keenness and a capacity for original work he had infinite patience and sympathy.

Finally, it is worthy of note that Holmes was one of the last representatives of those physicians of an earlier generation who depended entirely on the private practice of consulting medicine, whose research was carried out in their hard-won spare time, and who wholly lacked academic or other support. With the death of the voluntary hospitals this way of life ceased to be.

Holmes was appointed C.M.G. and C.B.E. during the First World War and was knighted in 1951. He was elected a Fellow of the Royal Society in 1935; he was an honorary member of numerous foreign medical societies, and received honorary degrees from the Universities of Dublin, Durham and Edinburgh and from the National University of Ireland. He married, in 1918, Rosalie, daughter of Brigade-Surgeon Jobson, and had three daughters.

F. M. R. WALSHE

Prof. William Wilson, F.R.S.

William Wilson died on October 14, 1965, at the age of 90. He retired in 1944 from the Hildred Carlile chair of physies at Bedford College, University of London, which he held from the time of its creation in 1921. He came from a farming family and spent his boyhood at Goody Hills in Cumberland. From the village school at Holme St. Cuthbert he obtained scholarships to the Aspatria Agricultural College and to the Royal College of Seience. At this stage, he found difficulty in changing his course of study from one in biological subjects and temporarily abandoned his scientific carcer for school teaching. He taught English in the Berlitz School of Languages in Dortmund for a time, but was able to return to scientific work by studying physics and mathematics in German universities. Later in life he often praised the freedom of choice which was given to students in Germany and held that the British system of examinations imposed an undesirable and discouraging rigidity.

His first published work, in the Annalen der Physik for 1907, is an extract from his Dr. Phil., Leipzig, inaugural dissertation. It is an account of experiments on photoelcctric emission and on the photoconductivity of such materials as silver iodide. He long retained an interest in the photoelectric effect and published a quantal theory of thermionic emission based on the idea that the electrons were ejected photoelectrically by quanta of radiation in thermal equilibrium. He showed that the temperature dependence would be similar to that deduced by $\mathrm{O}$. W. Richardson, who used non-quantal arguments. It later became clear that these photoelectrons could account for only a small fraction of the thermionic current.

After becoming an assistant lecturer at King's College, London, in 1906, his interest was aroused by the atomic speculations on nebulium of Prof. J. W. Nicholson, professor of mathematics at tho College, which antedated Bohr's theory of the hydrogen spectrum. In 1915 Wilson's famous paper "The Quantum Theory of Radiation and Line Spectra" appeared in the Philosophical Magazine. In this he first proposed the Wilson-Sommerfeld quantiza. tion rules in the form:

$$
\begin{aligned}
& \int p_{1} \mathrm{~d} q_{1}=\rho h \\
& \int p_{2} \mathrm{~d} q_{2}=\sigma h \\
& \int p_{3} \mathrm{~d} q_{3}=\tau h
\end{aligned}
$$

where $p, \sigma, \tau, \ldots$ are positive integers (including zero) and theintegrations are extended over the values $p_{s}$ and $q_{s}$ corresponding to the period $1 / v_{s}$. The $q$ are Hamiltonian generalized co-ordinates of position and the $p$ are their conjugate components of generalized momentum. The paper applied the rules to the simple harmonic oscillator, to find $E_{0}=p h v$. An application of statistical mechanies to an assembly of oscillators gave Plauck's radiation formula but failed to give the Bohr frequency relation:

$$
h \nu=E_{1}-E_{2}
$$

In 1916 appeared "The Quantum of Action", which preceded Sommerfeld's first paper on the subject. In this Wilson doduced that if elliptic orbits existed in the atom. they could only have a few discrete values of the eccentricity $\varepsilon$ given by

$$
\sqrt{1-\varepsilon^{2}}=\sigma /(p+\sigma)
$$

where $\sigma$ and $\rho$ are positive integers as before.

Wilson did not follow this up, but in the quite independent work of Sommerfeld on the other side of the firing lines in Germany it led to the idoa of space quantization and to a theory of the fine structure of the lines of hydrogen. In this theory the energies of the levels agreed with the values given later by the relativistic wave mechanics of Dirac.

The sharply defined elliptic orbits used in the theory are incompatible with the indeterminacy relations of Heisenberg, so that their success in explaining the fine structure must be regarded as an accidental coincidence. In this, the theory resembles many other steps forward in 
the history of quantum mechanics in which nearly every advance has been shown later to have contained some erroneous components.

Wilson's later work was mainly concerned with basic problems such as a search for a relation between general relativity, electromagnetism and quantum mechanics. In the final volume of his text-book Theoretical Physics, which appeared in 1940, he expressed the view that a unified theory may follow the ideas of Kaluza who, in 1925, suggested that the paths of particles were geodesics in a 5-dimensional continuum. The fifth dimension would be related to the conservation of charge.

In all his researches he chose difficult subjects which were insoluble with the state of knowledge at the time. In his last years he was engaged in speculations concerning the shapes of the spiral nebulae.

Wilson was a fluent and remarkable lecturer and teacher. He had an unusual gift for personal contact and discussion with each student, often during the course of a laboratory class. His Theoretical Physics, in three volumes, contains many short, clear and original derivations of formulae. After his retirement he published the Microphysical World and $A$ Hundred Years of Physics.

The latter contains valuable details of the history of recent ideas of the structure of the material world. It is at the same time an excellent, concise text-book of modern physics in which the human interest of the story helps the reader to follow the subtle arguments and experiments by which the facts have been established. The book is one of the "Hundred Years" series, but the title has perhaps deterred undergraduate students from appreciating its virtues as a source of information.

Wilson's wife died in 1957. $\mathrm{He}$ is survived by his son and his grandchildren.

H. O. W. RichardsoN

\section{Dr. Basil Roland Record}

DR. B. R. RECORD, senior principal scientific officer in the Ministry of Defence, head of the Biophysics Section of the Microbiological Research Establishment, Porton, died at his home in the New Forest on November 17, 1965. He was fifty-four years of age.

He was educated at King Edward School, Birmingham, and as a schoolboy, passionately interested in chemistry, carried out quite advanced chemical preparations in his garden-shed laboratory. With this interest he went on, naturally, to study chemistry at the University of Birmingham under the late Sir Norman Haworth and graduated with first-class honours in 1933 . His first research study, also carried out at Birmingham, under the direction of Dr. S. R. Carter, was in the field of physical chemistry-an investigation of the molecular weights of polysaccharide derivatives using osmotic pressure methods. The osmometer designed by Carter and Record for use with organic solvents formed, then, a notable advance in technique and is still quoted approvingly in modern texts.

In 1937, with the aid of an extended scholarship from the Department of Scientific and Industrial Research and with Sir Norman's encouragement, he was one of the earliest of those who went to work in Prof. Svedberg's laboratory in Uppsala to use the ultra-centrifugal and diffusion techniques then recently developed there. $\mathrm{He}$ found the 18 months he spent in Sweden in the quiet university town of Uppsala among the happiest of his working days, and it was there that he produced his very successful results on the physico-chemical characteristics of a series of methylated glycogens and of the specific polysaccharides from 'Types I, II and III pneumococcus. Although the publication of this work was much delayed, the observations must have been the earliest demonstration of the strong dependence of sedimentation and diffusion coefficients on concentration found with some materials.
Although he thought seriously of remaining longer in Sweden, where he found the way of life much to his liking, the prospect of approaching war sent him back to England in 1938 to join Drs. A. S. McFarlane and R. A. Kekwick, who had by then brought both a Svedberg ultra-centrifuge and Tiselius electrophoresis apparatus into operation at the Lister Institute. It is in striking contrast with present-day science that in his first year at the Lister Institute no financial support could be found for him from either the Lister or public funds. In 1939, however, he was awarded a coveted Beit Memorial Fellowship, which he held until he resigned it in 1940 to undertake more active war work. It was during this period at the Lister that he worked with R. A. Kekwick on a physico-chemical investigation of the development of diphtheria anti-toxin in the immunized horse and the characteristics of anti-toxin proteins, the work which he, in retrospect, thought of as his most successful.

From 1941 until 1944 he worked in the Army Operational Research Group under Brig. Schonland, and principally on radar predictors, field fire-control procedures (antiaircraft) and trials of new equipment. It was typical of him that, conceiving that he could not work freely and scientifically under senior army officers, he refused throughout to accept a commission though at much cost to himself in terms of income and the advantages of commissioned rank in war-time.

In 1944 he was released from the A.O.R.G. at the request of Sir Alan Drury to join the 'Medical Research Council-Lister Blood Products Unit' which had been set up at the Lister Institute to undertake human plasma fractionation and, initially, the preparation of fibrinogen and thrombin which, together with fibrin foam, were urgently required for war-time clinical application: at a later stage the work was extended to cover the production of $\gamma$-globulin and albumin. He had a marked aptitude, and took much pleasure in his engineering skills and contributed to the design of pilot plant equipment for plasma fractionation under aseptic conditions.

The final move in his career was made in 1947 when, at the urgent request of the director, Dr. D. W. Henderson, he took up an appointment at the Microbiological Research Establishment. Here he was made responsible for the formation of a biophysics unit together with an extensive freeze-drying laboratory, for which he designed a range of freeze-drying machinery. Under his guidance, physico-chemical investigations of several biologically important macromolecular systems were made, including, particularly, botulinus toxin and polyglutamic acid, the latter of interest both biologically and as a member of the then emerging field of polyelectrolyte systems. He was, however, most particularly concerned with the fundamental aspects of the survival of micro-organisms during the freeze-drying process.

His work was characterized by the most scrupulous attention to the conception, design, performance and analysis of experiment, by his insistence that deductions and conclusions were adequately based on experiment and by the preparation of careful, clearly written and unambiguous reports: nothing aroused his anger more than the inclusion of unwarranted speculation in a scientific paper. Although somewhat retiring, he had a strong personality, and he was devoted to the idea, perhaps no longer really possible, that a scientist should be personally engaged in experimental observation and, in consequence, showed no desire to form a large group of workers, but gathered and retained only a few bound to him by his integrity and friendship.

Conflicting with his laboratory-bound science was his wish to be actively engaged outdoors, and he was fortunate in having spent his last years in a house with a large woodland garden in the New Forest, which gave him the greatest pleasure.

R. G. WaILIS 